\title{
Adherence in a pavement rehabilitated with a polymeric grid used as interlayer
}

\author{
Héctor Luis Delbono, Carlos Alberto Giudice* \\ LEMAC, Centro de Investigaciones Viales, Universidad Tecnológica Nacional Facultad Regional La Plata, Calle 60 y 124,1900 La Plata, Argentina
}

\section{H I G H L I G H T S}

- Thermal properties of grid base material are modified by asphalt emulsion.

- Base material of geotextile must melt during application in hot of asphalt mix.

- The geosynthetic between concrete and asphalt mix improved the adherence.

- Deformations at maximum load were higher when a grid was used between layers.

- Energy absorbed increased when polymeric grid allowed the contact between layers.

\section{A R T I C L E I N F O}

\section{Article history:}

Received 16 October 2013

Received in revised form 26 December 2013

Accepted 27 December 2013

\section{Keywords:}

Pavement

Crack

Rehabilitation

Asphalt emulsion

Geosynthetic

Asphalt mix

Temperature

Adherence

\begin{abstract}
A B S T R A C T
A polymeric grid was placed between layers of a pavement with the aim of preventing the reflection of cracks from the base material to the upper layer. Results explain why the usual faults that occur in rehabilitated pavements: (i) chemical modifications of geosynthetic polypropylene determined by FTIR lead to changes in its melting point; (ii) the discontinuity or continuity of the interface observed by SEM depends on the application temperature of the asphalt mix and (iii) the adherence obtained in laboratory tests correlates perfectly with the quoted chemical modifications of geosynthetic polypropylene and the structure of interface in multilayer pavements.
\end{abstract}

(c) 2014 Elsevier Ltd. All rights reserved.

\section{Introduction}

In multilayer systems as pavements, the relative movement between the component layers constitutes an important source of cracks. A pavement works properly when it transmits the stress generated by traffic and weather conditions to all its thickness: its functioning is essential that it be as monolithic structure [1].

Polymeric grids are used in many fields of engineering [2-14]; in rehabilitation of pavements, these are inserted between the layers in order to retard the crack propagation pre-existing to a new tread layer [15-17].

When a grid is placed between asphalt layers, it is less likely to be present bond failures at the interface because they are related materials. On the other hand, pavements formed by layers of

\footnotetext{
* Corresponding author. Address: Calle 71 No. 485, 1900 La Plata, Argentina. Tel.: +54 2214822828 ; fax: +54 2214271537.

E-mail address: cagiudice@yahoo.com (C.A. Giudice).
}

materials of different nature can have low adherence, which results in a poor or no stress distribution in the total thickness of pavement and consequently, in the appearance of premature cracks in the bearing binder [18].

Failures by adherence are longitudinal displacements, which are located in areas of the road surface [19]. Lack of adequate adherence between layers leads to structures that work as two separate systems; in these circumstances, the upper layer must provide high rigidity to be able to absorb the loads by itself because otherwise there will be failures. An adequate adherence between the pre-existing and new bearing layer can be achieved through irrigation of a binder as an asphalt emulsion [20].

The aim of this investigation was to study the adherence of multilayer pavements, on laboratory scale, formed by a standard concrete, two modified asphalt emulsions with different melting points, a grid based on polyester fibers attached to a non-woven polypropylene geotextile and finally, conventional asphalt applied at different temperatures. 


\section{Materials and methods}

The determination of adherence was performed on multilayer pavements formed by:

\subsection{Standard concrete}

The design was carried out on laboratory scale; the composition is displayed in Table 1.

\subsection{Modified asphalt emulsions}

Two commercial products were used (Emulsion A and Emulsion B), differing primarily in the melting point; the main characteristics established in laboratory are included in Table 2. It is noteworthy that the quoted cationic emulsions were used since they showed in previous laboratory studies a high "affinity" at environment temperature with granitic aggregates selected for the design of the systems studied (similar values of surface tension of solid and liquid) and besides because in general the anionic emulsions evaporate the water more slowly, which could lead to problems if the geotextile is placed before the end of the coalescence of the emulsion ("melting" in cold of polymeric particles by plastic deformation).

\subsection{Geosynthetic}

A commercial polymeric grid was selected; it is coated by a bituminous layer based on polyester fiber bonded by points to a non-woven geotextile (needling) of polypropylene with a mesh size of $40 \times 40 \mathrm{~mm}$; these characteristics make it easy to install in construction, Fig. 1.

To characterize the materials, the softening points by ring and ball [21] and melting points [22] were determined on samples of non-woven polypropylene geotextile: (i) free of bituminous coating as supplied by the manufacturer (extraction solvent toluene), (ii) commercial and (iii) impregnated to saturation with both modified asphalt emulsions; complementally, ignition points [23] and of flame [21] of the above-mentioned materials were also determined due to its importance for safety reasons in construction. The softening points and of melting were determined in order to define three application temperatures of asphalt mix [22]

In parallel, Fourier Transform Infrared Spectroscopy (FTIR) was performed on the commercial base material and the material impregnated with the Emulsion $A$ in order to determine possible changes in its composition after exposure to temperatures of application of the asphalt mix.

For adherence tests, circular samples of $100 \mathrm{~mm}$ of diameter were randomly taken from a roll of $4 \mathrm{~m}$ wide by $150 \mathrm{~m}$ long.

\subsection{Asphalt mix}

The asphalt mix was designed in laboratory, Table 3. It corresponds to standard concrete based on a hot asphalt mix (dense, CAC D20 type); the CPA (Standing Committee of the Asphalt, Argentina, 2006 edition) defines as hot asphalt mix to the combination of a conventional or modified asphalt binder, aggregate (including filler) and additives such as adherence improvers, fibers, etc., manufactured in plants and placed in construction at temperatures above of ambient.

\subsection{Specimen preparation}

The specimens were prepared starting from a concrete cylinder with $100 \mathrm{~mm}$ diameter and $50 \mathrm{~mm}$ height. The modified asphalt emulsion was applied by irrigation ( 0.9 liter of solids per $\mathrm{m}^{2}$ ) on the top face (smooth, free of dust and lubricant, and in moisture equilibrium condition achieved under laboratory condition); then, before coalescence is completed, it were placed the geosynthetic and finally, the standard asphalt mix by compaction at three temperatures as mentioned (50 mm thick), Fig. 2.

Table 1

Composition and characterization of the standard concrete.

\begin{tabular}{|c|c|c|}
\hline Components & Volume, $\mathrm{cm}^{3}$ & Density, $\mathrm{g} \mathrm{cm}^{-3}$ \\
\hline Water & 163 & 1.00 \\
\hline Composite Portland cement 40 & 119 & 3.06 \\
\hline Coarse aggregate, $6: 12$ & 320 & 2.67 \\
\hline Fine aggregate & 38 & 2.65 \\
\hline Air & 15 & - \\
\hline Superfluidifier & 4 & 1.15 \\
\hline Flexural strength, MPa & & 4.5 \\
\hline Compressive strength, MPa & & 36.0 \\
\hline
\end{tabular}

Table 2

Main characteristics of modified asphalt emulsions.

\begin{tabular}{|c|c|c|c|}
\hline Test & ASTM standard & $\begin{array}{l}\text { Emulsion } \\
\text { A }\end{array}$ & $\begin{array}{l}\text { Emulsion } \\
\mathrm{B}\end{array}$ \\
\hline \multicolumn{4}{|l|}{ 1. On liquid emulsion } \\
\hline $\begin{array}{l}\text { Saybolt Furol viscosity a } 25^{\circ} \mathrm{C} \text {, } \\
\text { S }\end{array}$ & D88 & 33.7 & 31.5 \\
\hline $\begin{array}{l}\text { Asphalt residue by distillation, } \\
\text { g/100 g }\end{array}$ & $\begin{array}{l}\mathrm{D}-244,11 / 15 \\
\text { sections }\end{array}$ & 65.3 & 62.5 \\
\hline $\begin{array}{l}\text { Distillable hydrocarbons, } \mathrm{ml} / \\
100 \mathrm{ml}\end{array}$ & D1461 & 0.5 & 0.6 \\
\hline Water content, g/100 g & D95 & 37.5 & 39.6 \\
\hline $\begin{array}{l}\text { Settlement after } 5 \text { days, } \mathrm{g} / \\
100 \mathrm{~g}\end{array}$ & $\begin{array}{l}\text { D244, 29/32 } \\
\text { sections }\end{array}$ & 1.7 & 2.1 \\
\hline $\begin{array}{l}\text { Residue on sieve \# } 850 \mathrm{~mm}, \mathrm{~g} / \\
\quad 100 \mathrm{~g}\end{array}$ & $\begin{array}{l}\mathrm{D} 244,38 / 41 \\
\text { sections }\end{array}$ & 0.06 & 0.05 \\
\hline Particle charge & D244 & Positive & Positive \\
\hline \multicolumn{4}{|l|}{ 2. On distillation residue } \\
\hline Penetration in residue, $0.1 \mathrm{~mm}$ & D5 & 90 & 88 \\
\hline Ductility, $\mathrm{cm}$ & D113 & $>100$ & $>100$ \\
\hline Oliensis & D1370 & Negative & Negative \\
\hline \multicolumn{4}{|l|}{ 3. On coalesced solid } \\
\hline
\end{tabular}

Reference was formed by the standard concrete, the Emulsion A and the asphalt mix placed by compaction at a temperature set depending on the melting point of the geotextile; the specimen was prepared in triplicate in the same way that when included geosynthetics.

\subsection{Adherence tests}

It were used the methods by shear stress (LCB, Laboratorio de Caminos de Barcelona, España) and by direct tensile (LEMaC, Centro de Investigaciones Viales de la Universidad Tecnológica Nacional Facultad Regional La Plata, Argentina), respectively.

Both tests were conducted with the corresponding software and continuous recording of measurement; the conditions for these tests were as follows: test speed, $1.27 \mathrm{~mm} / \mathrm{min}$; temperature, $20 \pm 2{ }^{\circ} \mathrm{C}$ and boundary conditions, according to device to adherence measurement by shear stress or direct tensile. It is performed Scanning Electron Spectroscopy (SEM) on several interfaces of composites.

\subsubsection{Adherence by shear stress}

This test consisted of subjecting the specimens made in laboratory to a shear stress in the plane of discontinuity, by applying a bending load. The test allowed determining:

2.6.1.1. Adherence Tension $\tau$ y Adherence Coefficient CAd. The tension is calculated from the experimental results using the equation $\tau=0.0980665 P / 2 A_{T}$, where $\tau$ is the adherence tension (MPa), $P$ is the maximum load applied by the load cell and equivalent to twice of the reaction in the support acting on the plane of weakness $(\mathrm{kg})$ and, finally $A_{T}$ is the cross-sectional area of the specimen $\left(\mathrm{cm}^{2}\right)$.

With respect to the Adherence Coefficient, it was determined by relating the adherence of the specimen that included the asphalt emulsion/geogrilla ( $\tau$ Ad1, $\mathrm{kg} \mathrm{cm}^{-2}$ ) as interlayer with the maximum adherence obtained in the specimen that displayed an intimate contact at the interface of concrete/asphalt mix $\left(\tau \mathrm{Ad}_{\max }\right.$, $\mathrm{kg} \mathrm{cm}{ }^{-2}$ ), that is by using the equation $\mathrm{Cad}=\tau \mathrm{Ad} 1 / \tau \mathrm{Ad}_{\max }$.

2.6.1.2. Deformation L by slipping corresponding to the maximum load. The continuous recording allowed determining the Deformation $L$ corresponding to the maximum load, in mm.

2.6.1.3. Energy $T$ absorbed by the specimen. The work resisted by the test specimen, expressed in $\mathrm{kg} \mathrm{mm}$, was calculated by using the values obtained through continuous recording by the equation $T=\sum \Delta D \cdot \Delta$ Cav, where $\Delta D$ is the differential deformation by slipping between two successive records and $\Delta \mathrm{Cav}$ is the average value of load really applied at the interface (i.e. $P / 2$ ) for an interval equal to the corresponding $\Delta D$ deformation.

\subsubsection{Adherence by direct tensile}

This test consisted of subjecting the samples made in laboratory to a tensile stress; as well as for adherence by shear stress, it was determined the adherence, the Adherence Coefficient, the deformation by slipping and the energy absorbed by the specimen. 


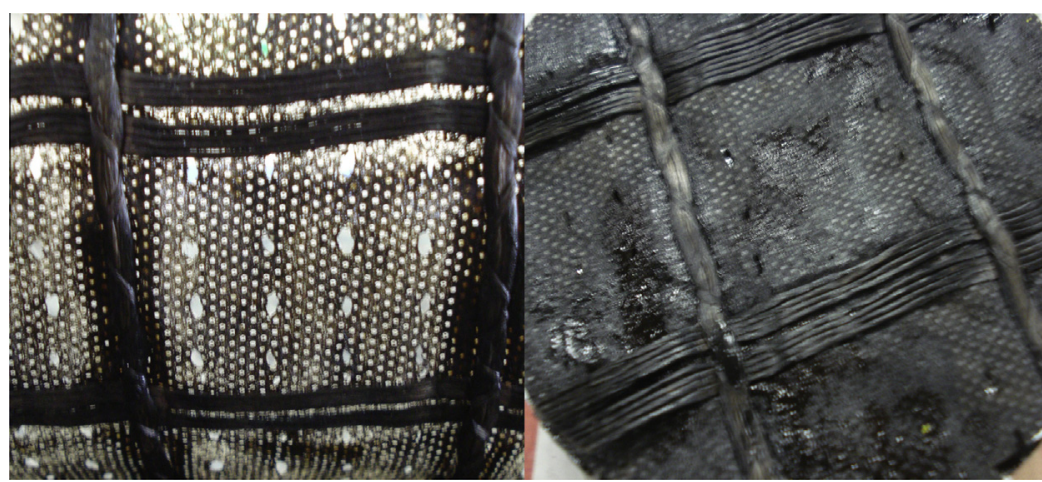

Fig. 1. Commercial geosynthetic (left) and impregnated with modified asphalt emulsion (right).

Table 3

Features of CAC D20 asphalt mix for road surface.

\begin{tabular}{|c|c|c|c|c|}
\hline \multicolumn{5}{|c|}{ Asphalt mix CAC D20 } \\
\hline \multicolumn{3}{|c|}{ Asphalt,\% } & & 5.0 \\
\hline \multicolumn{3}{|c|}{ Voids,\% } & & 4.8 \\
\hline \multicolumn{3}{|c|}{ Voids of mineral aggregate,\% } & & 16.1 \\
\hline \multicolumn{3}{|c|}{ Asphalt/void ratio,\% } & & 70.0 \\
\hline \multicolumn{3}{|c|}{ Rice $\operatorname{Dr}$ density, $\mathrm{g} \mathrm{cm}^{-3}$} & & 2.374 \\
\hline \multicolumn{3}{|c|}{ Marshall Dm density, $\mathrm{g} \mathrm{cm}^{-3}$} & & 2.260 \\
\hline \multicolumn{5}{|c|}{ Recovered aggregate size } \\
\hline Sieve & $\begin{array}{l}\text { Percent weight retained } \\
\text { accumulated }\end{array}$ & $\begin{array}{l}\text { Lower } \\
\text { limit }\end{array}$ & $\begin{array}{l}\text { Pass, } \\
\%\end{array}$ & $\begin{array}{l}\text { Upper } \\
\text { limit }\end{array}$ \\
\hline $1^{\prime \prime}$ & 0.0 & 100 & 100.0 & 100 \\
\hline $3 / 4^{\prime \prime}$ & 0.0 & 100 & 100.0 & 100 \\
\hline $1 / 2^{\prime \prime}$ & 15.6 & 85 & 84.4 & 100 \\
\hline$\# 4$ & 42.2 & 53 & 57.8 & 80 \\
\hline \# 10 & 58.4 & 35 & 41.6 & 60 \\
\hline \# 40 & 72.6 & 20 & 27.4 & 40 \\
\hline \# 80 & 83.9 & 10 & 16.1 & 30 \\
\hline \# 200 & 96.7 & 3 & 3.3 & 10 \\
\hline Bottom & 99.4 & - & 0.6 & - \\
\hline
\end{tabular}

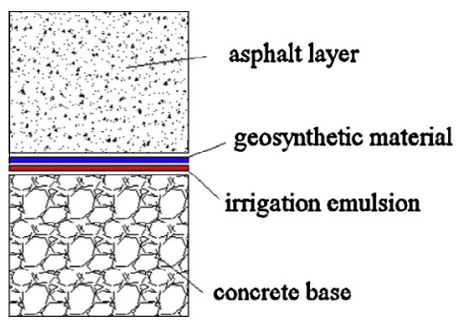

Fig. 2. Schematic specimen for testing.

\section{Results and discussion}

\subsection{Points of softening and melting}

The results of the tests, as above-mentioned carried out on polypropylene samples with and without bituminous coating and besides on samples after reaching the coalescence of the modified asphalt emulsion selected ( 7 days at $20^{\circ} \mathrm{C}$ and $65 \% \mathrm{RH}$ ), are included in Table 4.

The tests provided important data that make to the problem of adherence when this type of material is placed at the interface between layers; the melting point ranges were for: (i) polypropylene geotextile, free from bituminous coating provided by the manufacturer, between 145 and $155^{\circ} \mathrm{C}$; (ii) commercial polypropylene
Table 4

Features of geosynthetic.

\begin{tabular}{llll}
\hline Test & $\begin{array}{l}\text { Commercial } \\
\text { polypropylene }\end{array}$ & $\begin{array}{l}\text { Commercial } \\
\text { polypropylene/ } \\
\text { Emulsion A }\end{array}$ & $\begin{array}{l}\text { Commercial } \\
\text { polypropylene/ } \\
\text { Emulsion B }\end{array}$ \\
\hline Softening point, ${ }^{\circ} \mathrm{C}$ & $80-89$ & $42-49$ & $51-58$ \\
Melting point, ${ }^{\circ} \mathrm{C}$ & $142-156$ & $146-159$ & $169-178$ \\
Flash point, ${ }^{\circ} \mathrm{C}$ & 169 & 173 & 189 \\
Fire point, ${ }^{\circ} \mathrm{C}$ & 215 & 221 & 241 \\
\hline
\end{tabular}

Note: polyester fibers, $230-240{ }^{\circ} \mathrm{C}$ softening point and $240-260{ }^{\circ} \mathrm{C}$ melting point.

geotextile, between 142 and $156{ }^{\circ} \mathrm{C}$; (iii) polypropylene geotextile imbibed with Emulsion A, between 146 and $159^{\circ} \mathrm{C}$ and, finally (iv) polypropylene geotextile imbibed with Emulsion B, between 169 and $178^{\circ} \mathrm{C}$.

On the other hand, it is observed that the points of ignition and of flame are sufficiently far from the working temperatures, giving them a reasonable margin of safety.

Contemplating the melting points of the non-woven geotextile polypropylene imbibed in asphalt emulsions, temperatures of 140,160 and $180^{\circ} \mathrm{C}$ were selected for placement by compaction of the asphalt mix and $160^{\circ} \mathrm{C}$ for preparation of Reference.

\subsection{Fourier Transform Infrared Spectroscopy (FTIR)}

Fig. 3 shows the spectra obtained with a sample of original commercial geotextile and with other after being in contact with Emulsion A coalesced and heated in oven at $160{ }^{\circ} \mathrm{C}$ for $30 \mathrm{~min}$.

The spectra show the characteristic vibrations of these materials; thus, for example, peaks are observed at 2930, 2850, 950 and $650 \mathrm{~cm}^{-1}$, which may be attributed to the group $\mathrm{C}-\mathrm{H}$ of different hydrocarbon chains and at $1450 \mathrm{~cm}^{-1}$, which could correspond to the vibration of the $\mathrm{C}=\mathrm{C}$ double bond.

On the other hand, it is worth mentioning that the spectrum corresponding to the commercial material shows marked differences that one impregnated with modified asphalt emulsion; so for example, in the latter it can be inferred a chemical reaction due to stretching assigned to links $\mathrm{N}-\mathrm{H}$ (between 3550 and $3150 \mathrm{~cm}^{-1}$ ) and $\mathrm{C}=\mathrm{O}$ (in the region of $1750 \mathrm{~cm}^{-1}$ ).

These chemical modifications of geosynthetic polypropylene could be responsible of the changes in the melting points determined; it is inferred that the temperature and the contact time could affect the type and magnitude of the modification of the base material of geosynthetic.

\subsection{Adherence tests}

It is appropriate to note that the results obtained correspond to concrete specimens made in laboratory with a smooth surface and 


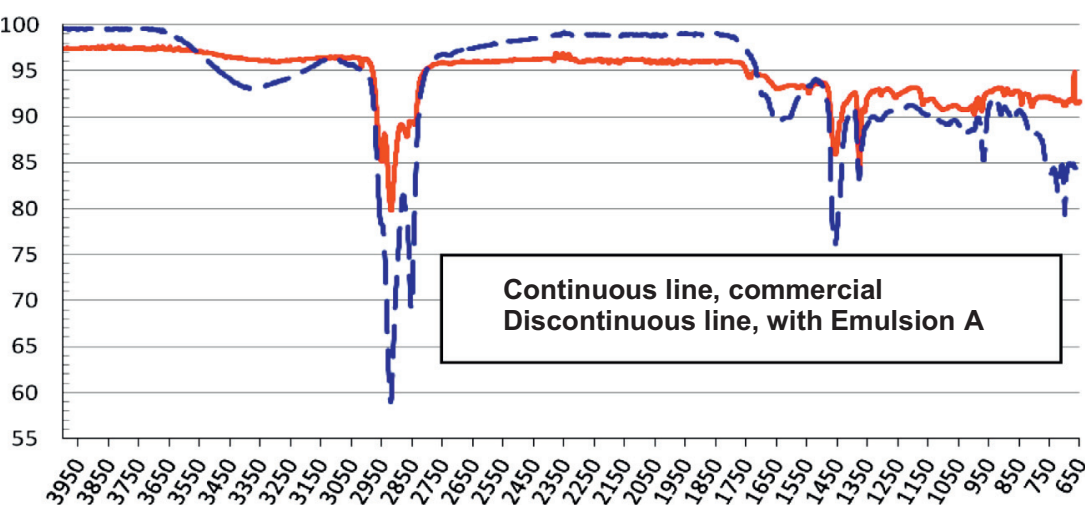

Fig. 3. FTIR of geosynthetics.

without irregularities, that is very different from what is usually found in construction; it follows that the surface state of the layer on which it is placed the material (roughness) is a significant variable.

Results of adherence by shear stress and by direct tensile are included respectively in Tables 5 and 6 (average of three determinations; standard deviations are enclosed in brackets). It is worth mentioning that the fracture took place entirely at the interface formed by the standard concrete and the rehabilitation layers (adhesive failure itself).

Analysis of the results indicates that:

\subsubsection{Adherence Tension $\tau$ y Adherence Coefficient CAd}

The results of testing by shear stress and by direct tensile indicate that, for both emulsions and in comparison with Reference, Tension $\tau$ and Coefficient CAd were greater for the geosynthetic with molten base and lower for the geosynthetic with unmelted base; as expected, the values of Tension $\tau$ and Coefficient CAd were modified practically in the same values. Thus, for Emulsion A and temperatures of 160 and $140{ }^{\circ} \mathrm{C}$, Tension $\tau$ and Coefficient CAd in testing by shear stress were respectively in average 1.2 times higher ( $18 \%$ increase) and 1.7 times lower (68\% reduction) while by direct tensile they were respectively in average 37.0 and 17.4 times higher. The highest values of Tension $\tau$ and Coefficient CAd would correspond to better performance of the system in service.

\subsubsection{Deformation $L$}

The results of testing by shear stress and by direct tension indicate that, for both emulsions and in comparison with Reference, Deformation $L$ corresponding to the maximum load was higher in the samples prepared with geosynthetic, both with and without the molten polypropylene. Thus, for Emulsion A and temperatures of 180,160 and $140^{\circ} \mathrm{C}$, in average the Deformation $L$ was respectively in testing by shear stress $0.77,0.79$ and $0.62 \mathrm{~mm}$ (Reference, $0.55 \mathrm{~mm}$ ) and by direct tensile 1.51, 1.55 and $0.76 \mathrm{~mm}$ (Reference, $0.59 \mathrm{~mm}$ ). These results indicate that the molten base material had lower deformation for greater load capacity, which would correspond to better performance of the system in service.

Although the Reference showed less deformation, it corresponds to a small load, so that the mentioned specimen would not be suitable for the demanding requirements in service.

\subsubsection{Absorbed energy}

Results indicate that in test by shear stress, for both emulsions and in comparison with Reference, the absorbed energy $T$ was greater for the geosynthetic with the melted base and less with unmelted base; thus, for example, for the Emulsion A and temperatures of 180,160 and $140{ }^{\circ} \mathrm{C}$, the absorbed energy in test by shear stress was on average about 1.9 times higher (93\% increase) and 1.5 times lower (54\% reduction), respectively.

With respect to the results obtained in test by direct tensile, values allow to reach conclusions similar to those mentioned above; thus, for the Emulsion A and temperatures of 180, 160 and $140{ }^{\circ} \mathrm{C}$, the absorbed energy was on average about 1.4 times higher (36\% increase) with the melted base and 1.7 times lower (67\% reduction) with unmelted base, respectively. The greater capacity to absorb energy by the system, with an acceptable deformation in service, would indicate better fitness or ability to resist the action of external loads.

\subsection{SEM micrographs}

Fig. 4 (left) allows to appreciate the discontinuity of structure formed by the concrete type, the geosynthetic impregnated with Emulsion A (for 7 days, after finishing the coalescence at ambient laboratory) and the asphalt mix applied to $140{ }^{\circ} \mathrm{C}$ (the base of geosynthetic is not melted). This discontinuity explains the low adherence obtained in laboratory tests.

Moreover, Fig. 4 (right) displays the continuous interface of afore-mentioned system when the asphalt mixture was applied at $160{ }^{\circ} \mathrm{C}$ temperature (the base material of geosynthetic is melted): the emulsion wetted adequately the layers of concrete

Table 5

Adherence by shear stress.

\begin{tabular}{|c|c|c|c|c|c|}
\hline Material & & Tension $\tau$, MPa & Coefficient CAd & Deformation $L, \mathrm{~mm}$ & Absorbed energy $T, \mathrm{~kg} \mathrm{~mm}$ \\
\hline \multirow[t]{3}{*}{ Emulsion A } & Geotextile, unmelted base $\left(140^{\circ} \mathrm{C}\right)$ & $0.07(0.02)$ & $0.31(0.02)$ & $0.62(0.02)$ & $71.84(1.63)$ \\
\hline & Geotextile, melted base $\left(160^{\circ} \mathrm{C}\right)$ & $0.26(0.02)$ & $1.18(0.59)$ & $0.79(0.03)$ & $301.82(3.26)$ \\
\hline & Geotextile, melted base $\left(180^{\circ} \mathrm{C}\right)$ & $0.25(0.02)$ & $1.15(0.57)$ & $0.79(0.03)$ & $302.44(4.08)$ \\
\hline \multirow[t]{3}{*}{ Emulsion B } & Geotextile, unmelted base $\left(140{ }^{\circ} \mathrm{C}\right)$ & $0.08(0.02)$ & $0.36(0.02)$ & $0.59(0.02)$ & $59.62(1.66)$ \\
\hline & Geotextile, unmelted base $\left(160^{\circ} \mathrm{C}\right)$ & $0.08(0.02)$ & $0.36(0.02)$ & $0.60(0.02)$ & $60.14(1.71)$ \\
\hline & Geotextile, melted base $\left(180^{\circ} \mathrm{C}\right)$ & $0.27(0.02)$ & $1.23(0.62)$ & $0.75(0.03)$ & $306.74(3.55)$ \\
\hline \multicolumn{2}{|c|}{ Reference (without geosynthetic) } & $0.22(0.02)$ & $1.00(0.00)$ & $0.55(0.02)$ & $156.34(2.45)$ \\
\hline
\end{tabular}


Table 6

Adherence by direct tensile.

\begin{tabular}{|c|c|c|c|c|c|}
\hline \multicolumn{2}{|l|}{ Material } & \multirow{2}{*}{$\begin{array}{l}\text { Tension } \tau, \mathrm{MPa} \\
0.87(0.03)\end{array}$} & \multirow{2}{*}{$\frac{\text { Coefficient CAd }}{16.11(1.63)}$} & \multirow{2}{*}{$\frac{\text { Deformation } L, \mathrm{~mm}}{0.76(0.03)}$} & \multirow{2}{*}{$\begin{array}{l}\text { Absorbed energy } T, \mathrm{~kg} \mathrm{~mm} \\
119.22(3.25)\end{array}$} \\
\hline Emulsion $\mathrm{A}$ & Geotextile, unmelted base $\left(140^{\circ} \mathrm{C}\right)$ & & & & \\
\hline & Geotextile, melted base $\left(160^{\circ} \mathrm{C}\right)$ & $1.85(0.05)$ & $34.25(1.73)$ & $1.55(0.06)$ & $249.68(4.82)$ \\
\hline & Geotextile, melted base $\left(180^{\circ} \mathrm{C}\right)$ & $1.74(0.04)$ & $32.22(1.70)$ & $1.51(0.05)$ & $246.71(4.73)$ \\
\hline \multirow[t]{3}{*}{ Emulsion B } & Geotextile, unmelted base $\left(140^{\circ} \mathrm{C}\right)$ & $0.80(0.03)$ & $14.81(1.59)$ & $0.74(0.03)$ & $149.45(4.01)$ \\
\hline & Geotextile, unmelted base $\left(160^{\circ} \mathrm{C}\right)$ & $0.79(0.03)$ & $14.62(1.72)$ & $0.74(0.02)$ & $100.12(2.89)$ \\
\hline & Geotextile, melted base $\left(180^{\circ} \mathrm{C}\right)$ & $1.94(0.08)$ & $35.92(1.84)$ & $1.48(0.05)$ & $247.61(4.62)$ \\
\hline \multicolumn{2}{|c|}{ Reference (without geosynthetic) } & $0.05(0.02)$ & $1.00(0.00)$ & $0.59(0.02)$ & $183.28(4.21)$ \\
\hline
\end{tabular}

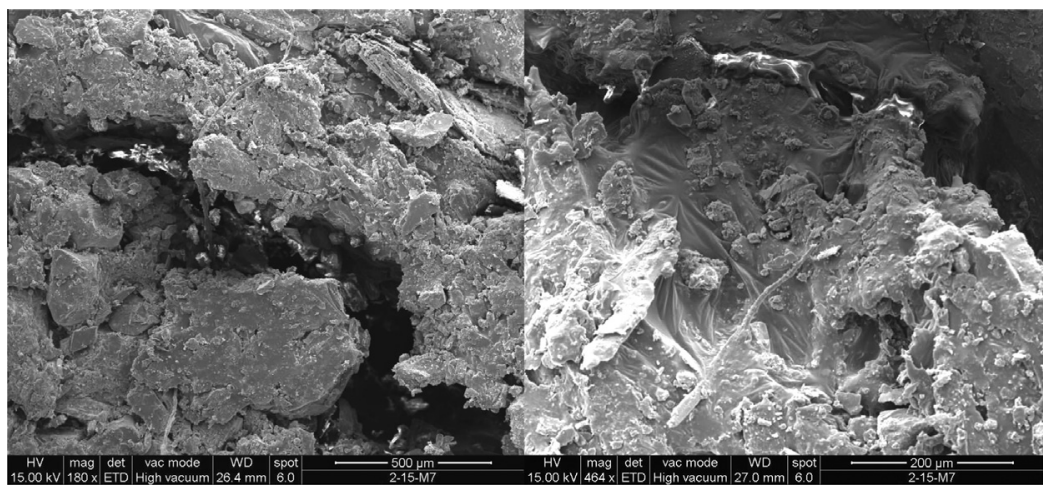

Fig. 4. SEM micrographs of system standard concrete/asphalt emulsion/geosynthetic/asphalt mix: discontinuous interface (left) and continuous (right).

and asphalt mix (i.e. phenomena of adhesion, penetration and propagation took place satisfactorily). The above quote would base the satisfactory results of adhesion obtained by shear and direct tensile.

\subsection{Visual and microscopic observations of the systems}

It was performed at different stages (these involved various periods of contact after incorporation of the hot mix asphalt followed by a subsequent rapid cooling) and allowed to infer the mechanism of formation.

For this purpose, it is considered the first law of thermodynamics, applied at constant pressure for closed systems and without gaseous components: the amount of heat is equal to the enthalpy. The enthalpy value of the asphalt mixture incorporated in hot is partially absorbed by the system components (concrete and polymer grid) and the remainder is dissipated by convection to the environment. The quoted absorbed heat can produce:

- Polyester fibers of geotextile: the bituminous layer covering the fiber absorbs thermal energy as sensible heat and softens. If the net enthalpy heat provided by the asphalt mix is enough (it depends on the selected temperature for application), the bituminous layer melts (it absorbs latent heat): the asphalt mixture adheres strongly on the fiber; in those cases where it is not so, the softened bituminous fiber layer forms a diffuse interface with the asphalt mixture: in this case the adhesion is also strong.

- Polypropylene of geotextile: the bituminous layer that also covers the polypropylene absorbs thermal energy as sensible heat and softens. If the net enthalpy provided by the asphalt mix is enough, the bituminous layer melts and then the polyethylene by conduction softens and subsequently melts: the asphalt mixture adheres strongly on the large area of the concrete base (it correlates with the continuous interface observed by SEM and the high adherence obtained in laboratory tests); on the other hand, if the enthalpy is not enough, the softened bituminous layer but not melted restricts significantly the wetting of the concrete surface (it correlates with the discontinuous interface observed by SEM and low adherence obtained in laboratory tests).

\subsection{Conclusions}

- The experiments carried out by the determination of adherence confirm that the geosynthetic is convenient to specify it for pavement rehabilitation in order to prevent reflection of cracks from the base material toward the bearing layer; the results indicate that the interface of system based on concrete/geosynthetic applied on the modified asphalt emulsion as bonding agent/asphalt mix was more favorable than that achieved by the concrete/asphalt emulsion/asphalt mix.

- Tests indicate that the introduction of geosynthetic between the concrete and the asphalt layer improved the adherence provided that the base material of geosynthetic is melted; otherwise, i.e. if the base material is not melted, the bond between layers was found damaged (discontinuous interface) and therefore, the structure displayed worse adherence than the concrete/asphalt emulsion/asphalt mix.

- When contacting geosynthetic with asphalt emulsion, properties of polypropylene of geotextile are modified with temperature, raising the melting point range according to emulsion type (FTIR spectra indicated a chemical change in its composition). It is concluded that the selection of the application temperature of the asphalt mix should be performed previously by determining the melting point of the base of the geotextile impregnated with the asphalt emulsion to be used.

- The system components should be selected so as to present a satisfactory behavior to the selected working temperature; thus, the base material of geosynthetic must melt to the application temperature of the asphalt mix and besides, the geosynthetic fibers must maintain their resistant condition at mentioned temperature (for example, a geosynthetic with polypropylene fibers should not be used at $160{ }^{\circ} \mathrm{C}$ ). 


\section{References}

[1] Tschegg EK, Kroyer G, Tan DM, Stanzl-Tschegg SE, Litzka J. Investigation of bonding between asphalt layers on road construction. J Trans Eng 1995;121(4):309-16.

[2] Button JW, Lytton RL. Guideline for using geosynthetics with HMA overlays to reduce reflective cracking. Information \& Technology Exchange Center (ITEC). Texas, USA; Rep. No 1777-P2; 2003.

[3] Shukla SK. Fundamentals of geosynthetics. In: Shukla SK, editor. Geosynthetics and their applications. London, England: Thomas Telford Publishing; 2002. p. $1-54$.

[4] Lopes ML. Soil-geosynthetic interaction. In: Shukla SK, editor. Geosynthetics and their applications. London, England: Thomas Telford Publishing; 2002. p. 55-79.

[5] Hsuan YG. Approach to the study of durability of reinforcement fibers and yarns in geosynthetic clay liners. Geotext Geomembr 2002;20(1):63-76.

[6] Hamidi A, Hooresfand M. Effect of fiber reinforcement on triaxial shear behavior of cement treated sand. Geotext Geomembr 2013;36(2):1-9.

[7] Consoli NC, Rotta GV, Prietto PDM. The influence of curing under stress on the triaxial response of cemented soils. Géotechnique 2000:50(1):99-105.

[8] Consoli NC, Cruz RC, da Fonsea AV, Coop MR. Influence of cement-voids ratio on stress-dilatancy behavior of artificially cemented sand. Geosynth Int 2012;138(1):100-9.

[9] Falorca IMCFG, Pinto MIM. Effect of short randomly distributed polypropylene microfibers on shear strength behavior of soils. Geosynth Int 2011;18(1):2-11.

[10] Ibrahim E, Diambra A, Russell AR, Muir Wood D. Assessment of laboratory sample preparation for fibre reinforced sands. Can Geotech J 2012;34(10): 69-79.

[11] Tang C, Shi B, Gao W, Chen W, Cai Y. Strength and mechanical behavior of short polypropylene fiber reinforced and cement stabilized clayey soil. Geotext Geomembr 2007;25(3):194-202.
[12] Koseki J. Use of geosynthetics to improve seismic performance of earth structures. Geotext Geomembr 2012;34:51-68.

[13] Tang CS, Shi B, Zhao LZ. Interfacial shear strength of fiber reinforced soil. Geotext Geomembr 2010;28:54-62.

[14] Thakur JK, Han J, Pokharel SK, Parsons RL. Performance of geocell-reinforced recycled asphalt pavement (RAP) bases over weak subgrade under cyclic plate loading. Geotext Geomembr 2012;35:14-24.

[15] Castro D, Ballester F. Influence of asphalt cement type and oven type of asphalt retention capacity of paving geotextiles. Geosynth Int 2006;13(2): $83-6$.

[16] Prieto JN, Gallego J, Pérez I. Application of the wheel reflective cracking test for assessing geosynthetics in anti-reflection pavement cracking systems. Geosynth Int 2007;14(5):287-97.

[17] Sholar GA, Page GC, Musselman JA, Upshaw PB, Moseley HL. Preliminary investigation of a test method to evaluate bond strength of bituminous tack coats. J Assoc Asphalt Pavement Technol 2004;73:771-806.

[18] Vanden Eynde $S$ et al. Thermal behaviour of homogeneous ethylene-1-octene copolímero and linear polyethylene at high pressures. Polymer 2000;41(9): 3411-23.

[19] Contreras Normabuena J et al. Análisis térmico de geosintéticos utilizados en la rehabilitación de pavimentos. Rev Chil de Ingeniería 2009;17(1): 95-100.

[20] West R, Zhang J, Moore J. Evaluation of bond strength between pavement layer. National Centre of Asphalt Technology, Alabama, USA; NCAT, Report 05$08 ; 2005$.

[21] ASTM D 36 (2006). Standard test method for softening point of bitumen (Ring and Ball Apparatus).

[22] ASTM D 1525 (2000). Standard test method for vicat softening temperature of plastics.

[23] ASTM D 92 (2001). Standard test method for flash and fire points by cleveland open cup tester. 